\title{
Collision Informer Using Augmented Reality
}

\author{
Aakash Agrawal ${ }^{1}$, Gourishankar Bawade ${ }^{2}$, Samruddha Shete $^{3}$, Roma Maity $^{4}$ \\ 1,2,3,4 Department of Computer Engineering, Sinhgad Institute of Technology, Lonavala, Savitribai, Phule Pune University, India
}

\begin{abstract}
This project proposes drivers assistant system architecture determined by image control techniques. A new camera is mounted on the vehicle front window to detect road markings and determine often the vehicle's situation with respect to the lane lines. A modified approach is proposed to accelerate the process in a computationally productive manner, thereby making it suitable for real time lane detection. Often the acquired impression sequences usually are analyzed as well as processed by means of proposed program, which easily detects the exact lane markings. The suggested system also captures almost any obstacle inside road and also detects the item in real time and give alert for it. The android application will have augmented certainty graphics designed and set in it.
\end{abstract}

Keywords: Augmented Reality; Driver Assitant; Image Processing

\section{Introduction}

This task proposes new driver assistant method architecture influenced by image application techniques. A good camera is actually mounted on the car front windowpane to identify road lane markings along with determine the very vehicle's job with respect to the lane lines. Some modified strategy is offered to speed up the process within a computationally reliable manner, therefore making it ideal for real time street detection. The exact acquired photograph sequences will be analyzed in addition to processed by way of proposed technique, which routinely detects the main lane ranges. The consist of system additionally captures any sort of obstacle during the road plus detects them in real time and provide alert for this. The google android application may have augmented simple fact graphics created and loaded in it.

\section{Purpose}

1)Minimize the crashes

2) Give forewarning for side of the road changing.

3) Give alert should there be any Target in front of car or truck.

4)Make travelling safer.

\section{Scope}

1) Driver should have Android phone.

2) Alert really should be effective enough.

\section{Augmented Reality Definition}

Augmented Reality (AR) is a live, direct or indirect, view of a physical, real-world environment whose elements are augmented (or supplemented) by computer-generated sensory input such as, graphics.

\section{Motivation}

Most of the accidents are driver errors and therefore there might be an opportunity to use new technologies like augmented reality (AR) to help drivers. This report represents our research in field of mobile Augmented Reality and describes the different technological approaches to achieve AR experience for collision avoidance.

\section{Proposed System}

The proposed vision-based marker-less tracking system aims at the use of real scene features for estimating the pose of a camera. The solution allows the user to move from using markers or any applicable tracking and poses estimation methods to using real scene features through an automatic process

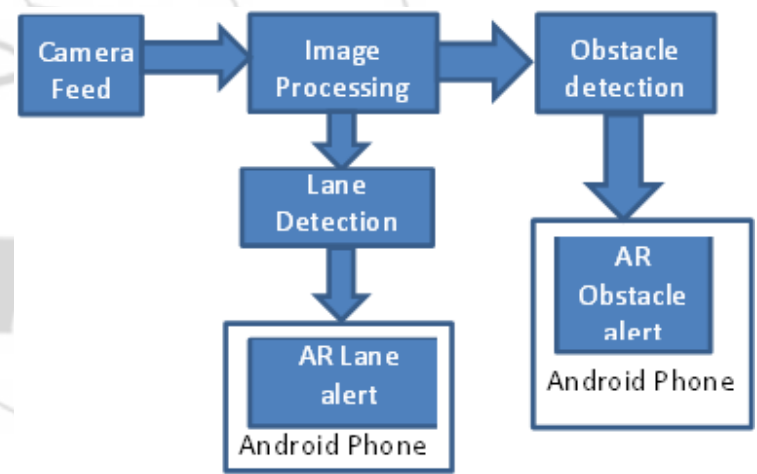

Figure 1: Proposed System Architecture

This process increases the success of the overall registration accuracy for the AR application. The basic idea is to first use the markers or any applicable tracking device for pose and motion estimation. The user could start using the system in his or her usual environment. As the user works with the current system an automated process runs in the background. This process remains hidden until the feature-based system decides to take over the pose estimation task from the other tracker. The takeover happens only after enough number of salient features are learned and the pose obtained from these are as good as the one provided by the external tracker. The automated process has two phases, i.e., (i) learning, and (ii) tracking for pose estimation.

\section{Implementation}

Technologies

1) OPEN CV

OpenCV [OpenCV] is an open source (see http://opensource.org) computer vision library available 


\section{International Journal of Science and Research (IJSR) \\ ISSN (Online): 2319-7064}

Index Copernicus Value (2013): 6.14 | Impact Factor (2015): 6.391

from http://SourceForge.net/projects/opencvlibrary. The library is written in $\mathrm{C}$ and $\mathrm{C}++$ and runs under Linux, Windows and Mac OS X. There is active development on interfaces for Python, Ruby, Matlab, and other languages. OpenCV was designed for computational efficiency and with a strong focus on real- time applications. OpenCV is written in optimized $\mathrm{C}$ and can take advantage of multicore processors. If you desire further automatic optimization on Intel architectures [Intel], you can buy Intel's Integrated Performance Primitives (IPP) libraries [IPP], which consist of low-level optimized routines in many different algorithmic areas. OpenCV automatically uses the appropriate IPP library at runtime if that library is installed.

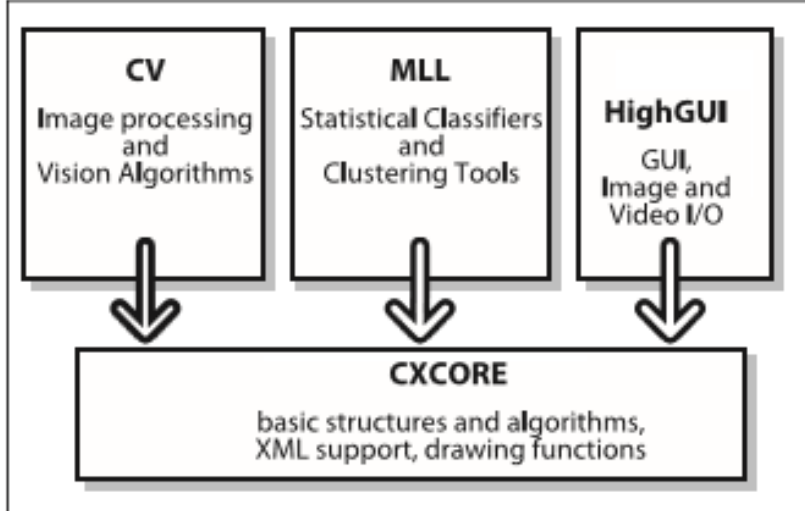

Figure 2: Open CV Architecture

What Is Computer Vision? Computer vision* is the transformation of data from a still or video camera into either a decision or a new representation. All such transformations are done for achieving some particular goal. The input data may include some contextual information such as "the camera is mounted in a car" or "laser range finder indicates an object is 1 meter away". The decision might be "there is a person in this scene" or "there are 14 tumor cells on this slide". A new representation might mean turning a color image into a grayscale image or removing camera motion from an image sequence.

\section{2) Unity 3d}

Unity 3D - an amazing game engine that enables you to create games and deploy them to a number of different devices, including (at the time of writing) the Web, PCs, iOS platforms, and WiiWare, with modules for Android and Xbox Live Arcade deployment in the works. You'll play a number of browser-based Unity 3D games to get a sense of what the engine can handle, from a massively-multi player online game all the way down to a simple kart racer. You'll download and install your own copy of Unity 3D, and mess around with the beautiful Island Demo that ships with the product.

\section{Software Modules and Algorithms}

\section{Eigen Object Recognition}

Helps recognize the images based on some mathematical computations which include the Eigen values and the Eigen vectors. The image with a minimum distance (less than the threshold distance) from the input image in the projection area is most suited to be the result.

\section{Blob Analysis Blob Analysis}

It is a fundamental technique of machine vision based on analysis of consistent image regions. As such it is a tool of choice for applications in which the objects being inspected are clearly discernible from the background.

\section{HSV Model}

HSL stands for hue, saturation, and lightness, and is often also called HLS. HSV stands for hue, saturation, and value, and is also often called HSB (B for brightness). A third model, common in computer vision applications, is HSI, for hue, saturation, and intensity.

The HSV colour model, also called HSB (Hue, Saturation, Brightness), defines a colour space in terms of three constituent components: - Hue is the colour type (such as red, magenta, blue, cyan, green or yellow). Hue ranges from 0-360 deg. - Saturation refers to the intensity of specific hue. Saturation ranges are from 0 to $100 \%$. In this work saturation is presenting in range $0-255$. - Value refers to the brightness of the colour. Saturation ranges are from 0 to $100 \%$. Value ranges are from $0-100 \%$. In this work saturation and value are presenting in range $0-255$.

\section{Cascade File}

Detect Road signs Detect the traffic sign, in any type, circular, hexagon, and rectangle, it's done by cascade file.

\section{Detect and Recognized Obstacle (ORB Algorithm)}

ORB (Oriented FAST and Rotated BRIEF) is a fast robust local feature detector its aim is to provide a fast and efficient alternative to SIFT. Provides Early Information: Distance \& Object Type.

Table 3: Literature survey

Literature survey shows the idea provided by the papers. The first paper provide the basic idea of system.

\begin{tabular}{|c|c|c|}
\hline $\begin{array}{c}\text { Paper } \\
\text { Title } \\
\end{array}$ & Author & is \\
\hline $\begin{array}{l}\text { Voluntary } \\
\text { vs } \\
\text { autometic } \\
\text { controls } \\
\text { over the } \\
\text { minds eyes } \\
\text { movement } \\
{[1]}\end{array}$ & $\begin{array}{l}\text { Underwood, } \\
\text { Crundall, } \\
\text { And Chapma }\end{array}$ & $\begin{array}{l}\text { Visual attention decline due to advancing } \\
\text { age can reduce the useful field of view } \\
\text { (UFOV), construed as the portion of the } \\
\text { visual field in which information can be } \\
\text { acquired during a single glimpse without } \\
\text { head or eye movements. UFOV decline } \\
\text { increases driver visual search time, vehicle } \\
\text { stopping distances, and crashes. }\end{array}$ \\
\hline $\begin{array}{c}\text { Highlighti } \\
\text { ng para- } \\
\text { dox } \\
{[6]}\end{array}$ & $\begin{array}{l}\text { Yeh and } \\
\text { Wickens }\end{array}$ & $\begin{array}{l}\text { This paper showed that cueing aided target } \\
\text { detection in an aviation visual search task. } \\
\text { They found target detec- tion accuracy was } \\
\text { enhanced when the object cued was not } \\
\text { conspicuous. }\end{array}$ \\
\hline \begin{tabular}{c|} 
A \\
Proposed \\
On- board \\
Driver \\
assis- tant \\
$\quad[7]$
\end{tabular} & $\begin{array}{l}\text { Ho And } \\
\text { Spence; } \\
\text { Scott And } \\
\text { Gray }\end{array}$ & $\begin{array}{l}\text { In this paper, On-board driver assist } \\
\text { applications may im- prove the ability to } \\
\text { perceive and react to roadway hazards in } \\
\text { drivers with age related visual information } \\
\text { processing impairments. By directing } \\
\text { driver attention, these sys- tems may } \\
\text { produce safety bene ts such as reduced RT } \\
\text { to hazardous situations and reduced } \\
\text { collision involvement }\end{array}$ \\
\hline
\end{tabular}




\section{International Journal of Science and Research (IJSR) \\ ISSN (Online): 2319-7064}

Index Copernicus Value (2013): 6.14 | Impact Factor (2015): 6.391

\section{Conclusion}

We come face to face with know about the importance of Augmented Real truth in various fields especially in automobile. By using this potential and getting technology, we can easily reduce the amount of accidents and gives safer vacation to people and with this safety bouquets it will also give comfort and high end feeling to opportunity seekers. So to put into practice the sensible driving, that AR systems will be key factor.

\section{References}

[1] Jonides J. Voluntary versus automated control on the minds eyes movement. In: Long JB, Baddeley OFFER, editors. Attention and performance IX. Erlbaum; Hillsdale, NJ: 1980. pp. 187-203.

[2] Any Fisher DL, Tan KC. Visual shows: The showcasing paradox. Human Factors. 1989; 31(1): 17-30.

[3] Yeh M, Wickens CD. Present signaling for augmented inescapable fact: Effects of "cue" reliability as well as image realism on consideration allocation and also trust calibration. Human Components. 2001; 43(3): 355-365.

[4] Naish JM. Combination of information and facts in superimposed visual grounds. Nature. 1964; 202: 641646.

[5] Lauber JK, Bray RS, Harrison RL, Hemingway JC, David BC. The operational examination of mind up exhibits for sencillo transport procedures. NASA/FAA level 3 survey. NASA Ames Research Heart; Moffett Arena, CA: 1982. No . A-8477; HUD- 12; NAS - 60: 1815; NASA-TP-1815)

[6] Wickens CONCEPT ALBUM, Long J. Object vs space- primarily based models of aesthetic attention: Benefits for the design of head-up features. Journal associated with Experimental Psychology: Applied. 1995; 1(3): 179-193.

[7] Caird JK, Horrey WJ, Edwards CJ. Effects of conformal along with non-conformal imaginative and prescient vision enhancement techniques on aged driver functionality. Transportation Exploration Record. 2001; 1759: 38-45Y. T. Yu, M. Farreneheit. Lau, "A comparison of $\mathrm{MC} / \mathrm{DC}$, MUMCUT and some other insurance policy coverage criteria just for logical decisions", Journal regarding Systems in addition to Software, june 2006, in media.

[8] Tufano DR . Automobile HUDs: Typically the Overlooked Questions of safety. Human Things. 1997; 39(2): 303-311.

[9] Azuma R. A questionnaire of augmented reality. Teleoperators and Virtual Environments. 1997; 6(4): 355-385.

[10] Azuma R, Baillot Y, Behringer R, Feiner S, Julier S, MacIntyre B. New advances in augmented reality. IEEE Pc Graphics plus Applications. i b?rjan p? tv?tusentalet; 21(6): 34-47.

[11] Kearney JK, Rizzo M, Severson J. Digital reality and even neuroergonomics. Within: Parasuraman Ur, Rizzo M, editors. Neuroergonomics: The brain in the office. Oxford School Press; The big apple, NY: 2008. pp. 253274.
[12]Ververs PM, Wickens CD. Head-up displays: Associated with clutter, screen intensity, together with display area on start performance. Often the International Journal of Aerial Psychology. 1998; 8(4): 377-403.

[13] Schall Mirielle, Jr., Rusch M, Lee J, Vecera S, Rizzo M. Destination without distraction: 236-236.

[14] Underwood G, Crundall D, Chapman P. Not bothered searching whilst driving: The exact role connected with experience within hazard recognition and typical surveillance. Ergonomics. 2002; 45(1): 1-12.

[15] Myers RS, Ball KK, Kalina TD, Roth DL, Goode KT. Relation with useful area of see and other selection tests to help on-road driving a car performance. Perceptual and Generator Skills. 2200; 91(1): 279-290.

[16] Owsley C, Tennis ball K, McGwin G, Jr ., Sloane MY FAMILY, Roenker DL, White MF, Overley THE PERFECT. Visual absorbing impairment and risk of motorized vehicle crash within older people. JAMA: The very Journal from the American Health Association. 98; 279(14): 1083- 1088.

[17] $\operatorname{Rog} \tilde{A} \subset$ L, PÃCbayle Big t. Deterioration in the useful image field utilizing ageing while in simulated driving in targeted visitors and its likely consequences meant for road safe practices. Safety Scientific disciplines. 2009; 47(9): 1271-1276.

[18]Ho H, Reed N, Spence J. Multisensory in-car warning impulses for collision avoidance. Human being Factors. 07; 49(6): 1107-1114.

[19] Al JJ, Grey R. An evaluation of tactile, visual, as well as auditory notifications for rear-end collision protection in artificial driving. Individual Factors. 08; 50(2): 264275.

[20] Ho F, Spence C. Assessing the effectiveness of various oral cues inside capturing some sort of drivers vision attention. Diary of Treatment solution Psychology. Put on. $2005 ; 11(3)$ : 157-174.

[21] Kramer AF, Cassavaugh And, Horrey WJ, Becic Elizabeth, Mayhugh JL. Influence of age and easy access warning gadgets on crash avoidance throughout simulated traveling. Human Issues. 2007; 49(5): $935-$ 949.

[22] A Proposed On- board Driver assistant Ho And Spence; Scott And Gray presented in this paper, On-board driver assist ; : Effects of increased reality hints on club hazard understanding. Journal involving Vision. the year 2010; 10(7), applications may im- prove the ability to perceive and react to roadway hazards in drivers with age related visual information processing impairments. By directing driver attention, these sys- tems may produce safety bene ts such as reduced RT to hazardous situations and reduced collision involvement 